\title{
SHEDDING OF THE ZONA PELLUCIDA OF THE MOUSE BLASTOCYST IN NORMAL PREGNANCY
}

\author{
S. BERGSTRÖM \\ Department of Human Anatomy, S 75220 Uppsala, Sweden \\ (Received 4th February 1972, accepted 20th Fune 1972)
}

The mouse blastocyst loses its zona pellucida shortly before it attaches to the uterine epithelium and starts the implantation process (Orsini \& McLaren, 1967; Restall \& Bindon, 1971; Bergström, 1972b). The nature of the zona loss is not well understood and evidence both for a lysis - a dissolution of the zona occurring essentially simultaneously around the blastocyst-and a hatchingan emergence of the blastocyst from the zona pellucida leaving an empty shell-has been furnished (see McLaren, 1970, for review).

Earlier investigations by light or electron microscopy on the loss of the zona pellucida of blastocysts in situ have been exclusively based on evidence provided by uteri fixed by immersion (cf. Potts \& Wilson, 1967). The mutual relations between the blastocyst and the uterine epithelium may be severely distorted by the vast tissue shrinkage accompanying this process.

The purpose of the present investigation was to test, firstly, whether the volume of the zona pellucida decreases as the process of zona loss approaches and, secondly, whether blastocysts in the very process of shedding display features compatible with lysis or hatching when the uteri are fixed in situ by perfusion through the abdominal aorta.

The zona volumes of blastocysts on Day 4 at 09.00 hours and at 21.00 hours were compared. The uteri of nineteen mice of the NMRI strain (ten and nine on these two occasions, respectively) were flushed with $2.5 \%$ glutaraldehyde in Soerensen's phosphate buffer. At the two different times, forty-four and twenty-eight zona-encased blastocysts, respectively, were photographed and mean zona thickness was assessed under the light microscope (three measurements at random on each blastocyst). Zona volumes were then calculated by assuming the blastocysts to be ellipsoids. In Day 4 blastocysts at 09.00 hours, the mean zona volume amounted to $1.26 \times 10^{5} \mu \mathrm{m}^{3}$ (S.E. $\pm 0.19 \times 10^{5} \mu \mathrm{m}^{3}$ ), while at 21.00 hours this volume averaged $1.19 \times 10^{5} \mu \mathrm{m}^{3}$ (S.E. $\pm 0.16 \times 10^{5} \mu \mathrm{m}^{3}$ ). The difference between the means corresponded to a decrease of $5.5 \%$ from 09.00 to 21.00 hours, which is not statistically significant when using a $t$ test. By 21.00 hours on Day 4 in the mouse strain used, some $35 \%$ of the blastocysts are known to be zona-free (Bergström, 1972b). From this comparison, it seems probable that the gradual thinning of the zona occurring during the course of Day 4 (Pl. 1, Figs 1 and 2) is related to blastocyst expansion (cf. McLaren, 1970) and not to lysis. Zonae of similar volumes have been reported for the rat (Kraicer, 1967). Since flushing in itself does not seem to divest the blastocyst of its zona (Bergström, 1972b), it appears that the zona is not gradually lysed 
while surrounding the blastocyst but is presumably shed during the process of hatching of the blastocyst.

Protruding trophoblast buds were seen in the light microscope in a few blastocysts collected at 21.00 hours on Day 4 (Pl. 1, Fig. 3). These were post-fixed in $1 \%$ osmium tetroxide, washed and freeze dried for scanning electron microscopy (Pl. 1, Fig. 5) according to a method previously described (Bergström, 1972a, c, d, e). The finding in the scanning electron microscope of different degrees of blastocyst expulsion from an otherwise intact zona gives indirect support for the existence of a hatching process.

Uteri fixed by perfusion were obtained on Day 5 at 01.00 hours from four mice of the NMRI strain. All the mice were injected with Pontamine Blue $15 \mathrm{~min}$ before laparotomy. The uteri were post-fixed with osmium tetroxide and Epon-embedded, allowing the dye-positive sites to be distinguished from the dye-negative regions. A total of thirty-two positive sites were sectioned, of which only three contained zona-encased blastocysts. These three sites were serially sectioned to see whether hatching had taken place. One site showed two immediately adjacent zona-encased blastocysts without visible cracks. The other two sites both showed blastocysts with a minor crack in the zona (Pl. 1, Fig. 4). The absence of any partially lysed zonae surrounding blastocysts in situ together with the presence of zona cracks in otherwise seemingly intact zonae surrounding such blastocysts in Epon-embedded material are regarded as indirect evidence in favour of hatching as the method whereby zonae pellucidae are usually shed from mouse blastocysts.

This investigation was supported by The Swedish Medical Research Council (Grant No. B70/72-12X-70). The technical assistance of Miss Barbro Pettersson is gratefully acknowledged.

\section{REFERENCES}

Bergström, S. (1972a) Preparation of ova for scanning electron microscopy. Ups. F. med. Sci. (in press).

BERGSTRÖM, S. (1972b) Shedding of the zona pellucida in normal pregnancy and in various hormonal states in the mouse. A scanning electron microscope study. Z. Anat. EntwGesch. 136, 143.

Bergström, S. (1972c) Delay of implantation by ovariectomy or lactation. A scanning electron microscope study. Fert. Steril. 23, 548.

Bergström, S. (1972d) Scanning electron microscopy of ovo-implantation. Arch. Gynäkol. (in press).

Bergström, S. (1972e) Interference with blastocyst implantation in the mouse by various antifertility compounds. A scanning electron microscope study. Contraception, 5, 215.

KRAICER, P. F. (1967) Studies on the mechanism of nidation. XXIV. Isolation and study of intrauterine ova from the rat: technique and observations. Int. F. Fert. 12, 320.

\section{EXPLANATION OF PLATE 1}

FiG. 1. Mouse blastocyst at 09.00 hours on Day 4. Note a rather prominent zona pellucida. $\times 530$.

Fig. 2. Mouse blastocyst at 21.00 hours on Day 4 . Note a thinned zona pellucida on an expanded blastocyst. $\times 530$.

Fig. 3. Early stage of hatching with a trophoblast bud protruding through the zona. $\times 530$.

Fig. 4. Mouse blastocyst at 01.00 hours on Day 5 in situ (Epon-embedded uterus, fixed by perfusion through the abdominal aorta). Note the crack in the zona (arrow). $\times 530$.

FIG. 5. Early stage of hatching. A trophoblast bud protrudes through the zona. Scanning electron micrograph. $\times 3300$. 
PLATE I

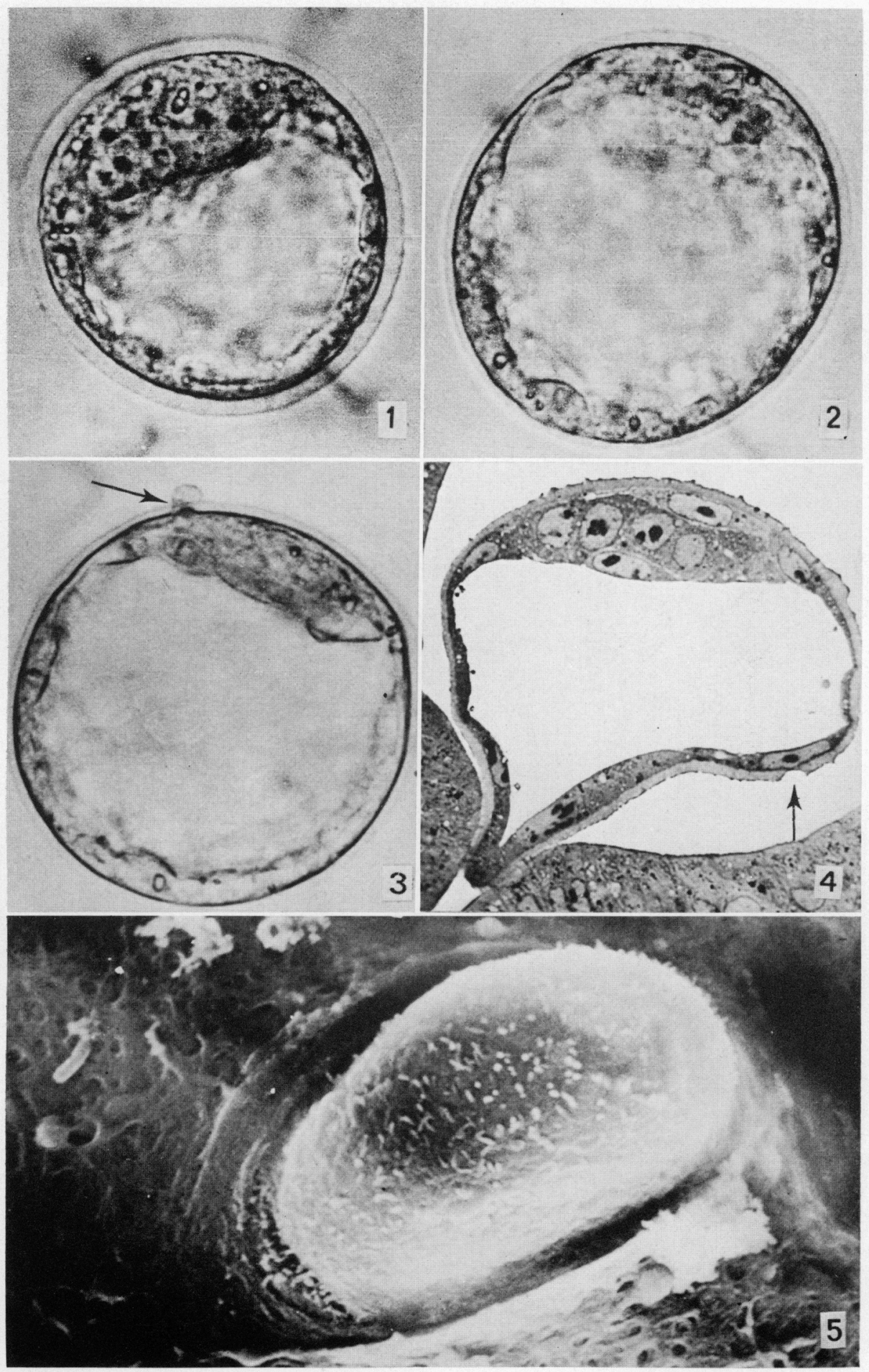

(Facing p. 276) 
McLaren, A. (1970) The fate of the zona pellucida in mice. J. Embryol. exp. Morphol. 23, 1.

Orsini, M. W. \& McLaren, A. (1967) Loss of the zona pellucida in mice and the effect of tubal ligation and ovariectomy. 7. Reprod. Fert. 13, 483.

Potts, D. M. \& Wilson, I. B. (1967) The preimplantation conceptus of the mouse at 90 hours post coitum. J. Anat. 102, 1.

Restall, B. J. \& Bindon, B. M. (1971) The timing and variation of preimplantation events in the mouse. 7. Reprod. Fert. 24, 423. 